\title{
SISTEM INFORMASI REKAM MEDIS DI BAGIAN FILING DI RUMAHSAKIT UMUM DAERAH Dr.MOEWARDI
}

\author{
Amik Novia Ratnasari ${ }^{1}$, Sri Sugiarsi ${ }^{2}$ \\ ${ }^{1,2}$ STIKes MitraHusada Karanganyar \\ noviepenguins@yahoo.co.id
}

\begin{abstract}
The objective of research was to find out information system in filing division.This study was a descriptive. The population consisted of 14 filing officers; the sample consisted of 5 filing officers taken using incidental sampling technique. The instrument of collecting data used was interview and observation guidelines. The methods of collecting data used were interview and observation. The data analysis was carried out using descriptive qualitative method. The result of research showed that the plot of storage procedure had been consistent with the SOP prevailing in Dr. Moewardi Local General Hospital. Data input SIMRS included medical record number, name, address, age, sex, objective of screening, payment method, entrance tracking, outget, storage user, patient master. In monitoring the medical record document, the filing officer used computerized and manual method, however in monitoring medical record document there were still miss file because of the officer fatigue and age factor, thereby delaying the service. Meanwhile, in medical record document transaction, the filing officer employed tracer for both medical record document borrowing and returning. The result of SIMRS found the number of medical record borrowed, data of unreturned medical record document, and medical record document use per day and per month. The conclusion of research was that there were some obstructions in monitoring medical record document related to miss file due to the officer fatigue and age factor.
\end{abstract}

Keywords: Information system, Filing

\begin{abstract}
Abstrak
Tujuan penelitian ini adalah menggambarkan sistem informasi di bagian filing. Jenis Penelitian ini adalah deskriptif. Populasi 14 petugas filing, sampel 5 petugas filing dengan menggunakan teknik Sampling Insidental. Instrument pengumpulan data adalah pedoman wawancara dan pedoman observasi. Cara pengumpulan data dengan wawancara dan observasi. Analisis datanya deskriptif kualitatif. Hasil penelitian menunjukkan bahwa alur prosedur penyimpanan sudah sesuai dengan SPO yang berlaku di RSUD Dr.Moewardi. Input data Sistem Informasi Rekam Medis meliputi nomor rekam medis, nama, alamat, umur, jenis kelamin, tujuan periksa, cara bayar, tracking masuk, outget,user simpan, master pasien. Dalam pemantauan dokumen rekam medis petugas filing menggunakan komputerisasi dan manual, akan tetapi dalam pemantauan dokumen rekam medis masih terdapat miss file dikarenakan petugas yang kelelahan dan juga faktor usia sehingga dapat memperlambat dalam pelayanan. Sedangkan dalam transaksi dokumen rekam medis petugas filing menggunakan tracer baik peminjaman dokumen rekam medis maupun pengembalian dokumen rekam medis. Ouput dari sistem informasi rekam medis di bagian filing dapat diketahuinya jumlah dokumen rekam medis yang dipinjam, data dokumen rekam medis yang belum kembali, mengetahui penggunaan dokumen rekam medis per hari dan per bulan.Simpulan dalam penelitian ini masih terdapat kendala dalam pemantauan dokumen rekam medis terkait dengan miss file dikarenakan petugas kelelahan dan faktor usia.
\end{abstract}

Kata kunci: Sistem Informasi, Filing

\section{PENDAHULUAN}

Menurut PermenkesNo.82 Tahun 2013 Tentang SIMRS adalah sistem teknologi informasi komunikasi yang memproses dan mengintegrasikan seluruh alur proses pelayanan rumah sakit dalam bentuk jaringan koordinasi, pelaporan dan prosedur administrasi untuk memperoleh informasi secara tepat dan akurat dan merupakan bagian dari Sistem Informasi Kesehatan. Pengelolaan SIMRS harus mampu meningkatkan dan mendukung proses pelayanan 
kesehatan di rumah sakit meliputi kecepatan, akurasi, integrasi, peningkatan pelayanan, peningkatan efisiensi, kemudahan pelaporan dalam pelaksanaan operasional.

Sistem Informasi sekumpulan unsur yang berhubungan antara satu dengan yang lainnya sedemikian rupa berproses mencapai tujuan tertentu, atau suatu tatanan dimana terjadi suatu kesatuan dari berbaga iunsur yang saling berkaitan secara teratur menuju pencapaian unsure dalam batas lingkungan tertentu (Rustiyanto,2010). Informasi yang dihasilkan di unit filing yaitu penggunaan DRM, kelengkapan isi dokumen rekam medis, daftar dokumen rekam medis yang siap diretensi, dokumen rekam medisdimusnahkan,formulir yang diabadikan (Sudra,2013).

Hasil penelitian Nugroho (2014) menyatakan bahwa petugas filing dengan petugas unit terkait harus berkoordinasi dengan baik untuk memahami betul tentang isi prosedur tetap pelayanan di bagian filing. Penyimpanan berkas RM di filing secara garis besar belum sesuai dengan prosedur tetap yang disahkan oleh direktur rumah sakit, hal ini diketahui bahwa petugas filing sering kali mengalami keterlambatan dalam menerima bekas rekam medis yang siap disimpan.

Berdasarkan survei, SIMRS di RSUD Dr.Moewardi menggunakan Web dan saat ini sudah terintegerasi sehingga di instalasi rekam medis dari unit satu ke unit yang lainya sudah terhubung. RSUD Dr.Moewardi merupakan rumah sakit tipe A yang menjadi pusat rujukan di jawa tengah bagian timur. Dengan banyaknya jumlah pasien yang berkunjung maka sistem informasidi bagian filing sangat dibutuhkan untuk menunjang pelayanan kesehatan. Di RSUD Dr.Moewardi sistem informasi di bagian filing masih terdapat kendala yaitu input data dilakukan secara berulang jika terjadi trouble jaringan dan salah penempatan dokumen rekammedis yang dikarenakan petugas kelelahan dan faktor usia, sehingga dapat menghambat pelayanan pasien. Tujuan penelitian ini adalah mengetahui gambaran sistem Informasi Rekam Medis Di Bagian Filing di RSUD Dr.Moewardi

\section{METODE PENELITIAN}

Jenis Penelitian yang digunakan adalah deskriptif yaitu menggambarkan sistem informasi di bagian filing di RSUD Dr.Moewardi. Subjek dalam penelitian ini adalah 5 petugas filing di RSUDDr.Moewardi.Objek dalam penelitian ini adalah sistem informasi rekam medis bagian filing di RSUD Dr.Moewardi.Instrumen pengumpulan data adalah Pedoman wawancara berupa daftar pertanyaan yang sudah tersusun dengan baik untuk mendapatkan informasi tentang pelaksanaan sistem informasi manajemen rumah sakit di unit filing rumah sakit. Dan pedoman observasi penelitian ini mengenai sistem informasi manajemen rumah sakit di unit filing rumah sakit.Teknik pengolahan dan analsis data meliputi; reduksi, penyajian dan penarikan kesimpulan.

\section{HASIL}

\section{Alur prosedur penyimpanan dokumen rekam medis di bagian filing di RSUD Dr.Moewardi}

Petugas filing di RSUD Dr.Moewardi dalam menyimpan dokumen rekam medis menggunakan sistem penyimpanan sentralisasi (Dokumen rekam medis disimpan dalam satu map baik Rawat Jalan, Rawat Inap maupun Gawat Darurat) dan menggunakan sistem penjajaran Terminal Digit Filing (TDF)atau berpedoman pada dua angka akhir. Penyimpanan di bagian filing di RSUD Dr.Moewardi sudah menggunakan roll o'pack namun masih ada dokumen rekam medis yang sengaja disimpan didalam rak.

Berdasarkan hasil wawancara SIMRS filing ditinjau dari aspek alur prosedur penyimpanan di bagian filing sebagai berikut:

Dokumen rekam medis dari poli diambil oleh petugas distributor kemudian ditracking masuk, kemudian dikirim ke filing, dokumen rekam medis oleh petugas filing dilakukan penjajaran $T D F$ setelah selesai dokumen rekam medis selanjutnya dimasukkan ke rak filing

Petugas filing $1 \& 2$

Namun demikian ada petugas yang menjelaskan alur prosedur penyimpanan di bagian filing sebagai berikut:

Pertama dokumen rekam medis dikelompokkan sesuai urutan nomor rekam medis kemudian dimasukkan ke rak filing sesuai nomor rekam medis

Petugas filing $3 \& 4$

Setelah pasien selesai pemeriksaan kemudian dokumen rekam medis pasien diberikan kepada petugas distributor dengan buku ekspedisi dari setiap poli setelah itu petugas distributor 
mentracking masuk dengan menggunakan nomor rekam medis, selanjutnya dokumen rekam medis disimpan ke filing menurut rak dan urutan nomor rekam medisnya.

Petugas filing 5

\section{Input data SIMRS di bagian filing di RSUD dr.Moewardi}

Petugas filing RSUD Dr.Moewardi dalam menginput data dikomputer menggunakan password agar dapat mengakses ke menu utama data pasien, apabila petugas salah dalam memasukkan kata kunci maka menu pelayanan memasukkan data tidak dapat diakses. Masing- masing petugas filing mempunyai password sendiri-sendiri, sehingga semua petugas bisa membuka di menu utama. Jadi kerahasian rekam medis yang ada di komputerisasi bisa terjaga dengan baik. Namun terputusnya jaringan internet dan mati listrik menjadi kendala dalam penginputan data SIMRS.

Berdasarkan hasil wawancara SIMRS filing ditinjau dari aspek input data SIMRS di bagian filing sebagai berikut:

Input data SIMRSnya yang pertama tracking masuk dari distribusi dokumen rekam medis, yang kedua outget dari ruang filing, yang ketiga pengecekan data apabila dokumen rekam medis tidak diketemukan (habis mondok atau masih di ruang filing), user simpan dokumen rekam medis rawat inap selesai proses pengolahan data (assembling, koding, analising).

Petugas filing 1, 2 \& 3

Namun demikian ada petugas yang menjelaskan input data SIMRS di bagian filing sebagai berikut:

Yang diinput adalah nomor rekam medis, nama pasien, alamat pasien, poli yang dituju pasien, cara bayar pasien (umum, bpjs, PKMS (Pemeliharaan Kesehatan Masyarakat Surakarta)).

Petugas filing 4 \& 5

\section{Pemantauan dan transaksi dokumen rekam medis di bagian filing di RSUD dr.Moewardi}

Dalam pemantauan dokumen rekam medis petugas filing di RSUD Dr.Moewardi menggunakan komputerisasi dan manual. Jika menggunakan komputerisasi petugas filing dapat melihat dari tanggal keluar dokumen rekam medis pada lembar master pasien. Jika menggunakan manual maka petugas filing dapat melihat pada buku ekspedisi di bagian filing.

Dalam transaksi dokumen rekam medis petugas filing di RSUD Dr.Moewardi menggunakan tracer baik peminjaman dokumen rekam medis maupun pengembalian dokumen rekam medis.

Berdasarkan hasil wawancara SIMRS filing ditinjau dari aspek pemantauan dan transaksi dokumen rekam medis di bagian filing sebagai berikut:

Dalam pemantauan dokumen rekam medis apabila petugas tidak menemukan dokumen rekam medis dirak penyimpanan maka dapat dilihat dari kunjungan terakhir pasien dari master pasien. Untuk peminjaman dokumen rekam medis menggunakan tracer untuk mengetahui dokumen rekam medis keluar pada hari apa dan posisi dokumen, yang meminjam dokumen rekam medis selain dari poli dan bangsal yaitu dari mahasiswa/penelitian, dokter/ residen, anggaran/pengeklaiman, dan asuransi.

Petugas filing 1

Namun demikian ada petugas yang menjelaskan alur prosedur penyimpanan di bagian filing sebagai berikut:

Pemantauan dokumen rekam medis pasti ada miss file penyebabnya itu karena salah penempatkan dokumen saat pengembalian dokumen, usia, pengelihatan. Peminjaman dari poli pendaftaran langsung keluar tracer, penelitian, peminjaman dokumen rekam medis lama, dari dinkes/puskesmas guna pelacakan penyebab bayi meninggal menggunakan buku ekspedisi dari bagian rekam medis dimasukkan melalui komputer agar mudah melacaknya, ada petugas sendiri untuk penelitian di peminjaman.

Petugas filing 2

Miss file ada tetapi bias dicari penyebabnya peletaan dokumen rekam medis yang salah, dokter meminta dokumen rekam medis tanpa menulis dibuku ekspedisi, pasien salah mendaftar poli. yang meminjam dokumen rekam medis itu poli, bangsal,keuangan, perawat, asuransi, dan dokter.

Petugas filing $3 \& 4$

Ada miss file tetapi juga ketemu. Peminjaman itu misalnya dari asuransi selesai mendapatkan 
tanda tangan dokter baru dikembalikan ke filing, ada penelitian tapi dokumen rekam medis sudah disiapkan tetapi si peneliti tidak dating sehingga dokumen rekam medis terlambat untuk kembali ke filing.

Petugas filing 5

\section{Hasil (out put) dari SIMRS di bagian filing RSUD Dr.Moewardi}

Hasil (out put) dari SIMRS di bagian filing RSUD Dr.Moewardi adalah informasi yang terkait dengan jumlah dokumen rekam medis yang dikeluarkan setiap harinya dari rak penyimpanan untuk memenuhi permintaan, kunjungan terakhir pasien dan dokter yang memeriksa, serta mempermudah cara kerja petugas rekam medis dan semua petugas yang berkaitan dengan pasien.

Berdasarkan hasil wawancara SIMRS filing ditinjau dari aspek hasil (out put) SIMRS di bagian filing sebagai berikut:

Hasil dari SIMRS mengetahui jumlah dokumen rekam medis yang dipinjam, data dokumen rekam medis yang belum kembali, mengetahui penggunaan dokumen rekam medis per hari, mengetahui penggunaan dokumen rekam medis per bulan.

Petugas filing 1,2,3,4, \& 5

\section{PEMBAHASAN}

Alur prosedur penyimpanan dokumen rekam medis di bagian filing di RSUD dr.Moewardi

Di RSUD Dr.Moewardi menggunakan sistem penyimpanan secara sentralisasi yaitu sistem penyimpanan dengan cara menyimpan dokumen rekam medis rawat jalan, rawat inap maupun gawat darurat dalam satu map, dengan menggunakan sistem penjajaran Terminal Digit Filing yaitu mensejajarkan dokumen rekam medis berdasarkan urutan nomor rekam medis pada 2 angka kelompok akhir. Di RSUD Dr.Moewardi sudah menggunakan roll o'pack dan sebagian lainnya masih disimpan di rak kayu. Dokumen rekam medis yang sudah selesai pelayanan atau penelitian selanjutnya ditracking masuk oleh petugas distributor dan kemudian dikirim ke bagian filing. Alur penyimpanan yang dilakukan oleh petugas filing sudah sesuai dengan Standar Prosedur Operasional No.Dokumen RSDM/SPO.A/RM/013 tentang Dokumen Rekam Medis Pasien yang berlaku di RSUD Dr.Moewardi.

\section{Input data SIMRS di bagian filing di RSUD Dr.Moewardi}

Pengelolaan informasi di bagian filling menggunakan sistem komputerisasi. Dalam penginputan data dikomputer menggunakan user dan password agar dapat mengakses ke menu utama data pasien. apabila petugas salah dalam memasukkan kata kunci maka menu pelayanan memasukkan data tidak dapat diakses. Sehingga kerahasiaan rekam medis yang ada di komputer bisa terjaga dengan baik. Kendala penginputan data SIMRS di filing adalah terputusnya jaringan internet dan mati listrik. Namun penyelesaian kendala tersebut dengan pencatatan secara manual dengan cara menulis dibuku ekspedisi di filing. Input data di bagian filing meliputi :

a. Nomor Rekam Medis

b. Nama

c. Alamat

d. Umur

e. Jenis Kelamin

f. Tujuan periksa

g. Cara bayar

h. Tracking masuk adalah untuk bukti bahwa petugas distributor sudah mengambil dokumen rekam medis dari poliklinik dan disetorkan ke ruang filing. Langkah-langlah tracking masuk:

1) Membuka SIRS

2) Klik admision

3) Klik pendaftaran

4) Klik tracking buku status

5) Kemudian klik tracking masuk

6) Kemudian pilih salah satu poliklinik reguler atau cendana(paviliun).

7) Kemudian mengisi nomor rekam medis pasien setelah itu di enter jika sudah berwarna biru bukti ahwa dokumen rekam medis sudah masuk.

i. Outget adalah bukti bahwa rekam medis filing sudah mengirim dokumen rekam medis ke poliklinik.Langkah-langlah outget:

1) Membuka SIRS

2) Klik admision

3) Klik pendaftaran

4) Klik tracking buku status

5) Kemudian klik outget

6) Kemudian pilih salah satu poliklinik reguler atau cendana(paviliun). 
7) Kemudian mengisi nomor rekam medis pasien setelah itu di enter jika sudah berwarna biru bukti bahwa dokumen rekam medis sudah keluar.

j. User simpan adalah dokumen rekam medis dari rawat inap selesai proses pengolahan data (asembling, koding, analising).

k. Master pasien adalah untuk mengetahui posisi dokumen rekam medis.

Apabila dalam pengisian data tidak lengkap maka sistem secara otomatis tidak dapat menyimpan data pasien. Hal ini sesuai dengan pernyataan Rustiyanto (2010) yang menyatakan bahwa input data, Sumber data / informasi untuk menunjang upaya kesehatan dan manajemen kesehatan, instrumen pencatatan data, sumber daya (tenaga, biaya, fasilitas) untuk pengelolaan dan pemanfaatan data / informasi.

\section{Pemantauan dan transaksi dokumen rekam medis di bagian filing di RSUD Dr.moewardi}

Pemantauan dokumen rekam medis di filing menggunakan komputer dan manual. Jika menggunakan komputer petugas filing dapat melihat dari tanggal keluar dokumen rekam medis pada lembar master pasien. Namun dalam pemantaun dokumen rekam medis masih terdapat kendala yaitu trouble jaringan yang dikarenakan adanya masalah dalam IPDE seperti rusaknyanya kabel UTP. Jika menggunakan manual maka petugas filing dapat melihat pada buku ekspedisi di bagian filing. Dalam pemantauan dokumen rekam medis masih terdapat kendala yaitu salah letak dokumen rekam medis atau tidak adanya dokumen rekam medis di rak penyimpanan (misfile) yang disebabkan petugas yang kelelahan atau faktor usia dari petugas, dan dokumen yang salah masuk poliklinik. Kendala tersebut dapat memperlambat pelayanan kesehatan.

Dalam transaksi dokumen rekam medis petugas filing di RSUD Dr.Moewardi menggunakan tracer baik peminjaman dokumen rekam medis maupun pengembalian dokumen rekam medis. Hal ini sesuai dengan pernyataan Sudra (2013) yang menyatakan bahwa digunakannya tracer sebagai pengganti dokumen rekam medis yang sedang digunakan dan untuk penghitungan tingkat penggunaan dokumen rekam medis.

Peminjaman dokumen rekam medis selain dari poliklinik dan bangsal, ada pihak lain yaitu mahasiswa untuk penelitian, dokter/residen untuk penelitian dan kasus, anggaran untuk pengeklaiman, asuransi, peminjaman dokumen rekam medisnya menggunakan buku ekspedisi.

Peminjaman dari pihak luar harus melalui kepala rekam medis kemudian di buatkan memo yang berisi nama peminjam, institusi dari peminjam, tanggal peminjaman, keperluan peminjaman, nomor dokumen rekam medis yang dipinjam dan ditandatangani oleh kepala rekam medis, waktu peminjaman dokumen rekam medis tersebut perharinya 15 dokumen rekam medis. Alur peminjaman di bagian filing sudah sesuai dengan Standar Prosedur Operasional No.Dokumen RSDM/SPO.A/RM/017 tentang Peminjaman Berkas Rekam Medis yang berlaku di RSUD Dr.Moewardi. Hal tersebut sesuai dengan pernyataan Amsyah (2003) yang menyatakan bahwa jika arsip tersebut dipinjam oleh orang lain dan bukan oleh petugas file itu sendiri, maka keluarnya arsip dari file haruslah dicatat. Bahkan kalau perlu biar petugas file sendiri yang mempergunakan, terutama bila agak lama, seyogianya juga dilakukan pencatatan. Sistem pengawasan ini perlu agar semua dokumen dapat diketahui apakah sedang berada di dalam file atau sedang di luar file.

\section{Hasil (out put) dari SIMRS di bagian filing RSUD Dr.moewardi}

Hasil dari SIMRS di bagian filing yaitu mengetahui penggunaan dokumen rekam medis perhari, mengetahui penggunaan dokumen rekam medis perbulan, dokter yang memeriksa, mengetahui kunjungan terakhir pasien untuk memprediksi masa retensi dokumen rekam medis, dengan cara mencantumkan tanggal kunjungan terakhir pada SIMRS akan mempermudah dalam mencari DRM yang akan di retensi, mempermudah petugas rekam medis dan semua petugas yang berkaitan dengan pasien.

Kepala di bagian filing merekap jumlah kunjungan pasien per hari berdasarkan jenis kunjungan pasien rawat jalan dan penelitian. Jumlah rata rata penggunaan dokumen rekam medis perharinya kurang lebih 1000 dokumen rekam medis. Hal ini sesuai dengan pernyataan Rustiyanto (2010) yang menyatakan bahwa output, pemanfaatan data / informasi untuk menunjang manajemen dan pengembangan kegiatan pelayanan kesehatan di rumah sakit. 


\section{SIMPULAN}

1. Alur prosedur penyimpanan di RSUD Dr.Moewardi sudah sesuai dengan Standar Prosedur Operasional yang berlaku di RSUD Dr.Moewardi.

2. Input data SIMRS di bagian filing di RSUD Dr.Moewardi adalah nomor rekam medis, nama, alamat, umur, jenis kelamin, tujuan periksa, cara bayar, tracking masuk, outget, user simpan, master pasien. SIMRS tersebut sudah terintegrasi dengan pendaftaran.

3. Dalam pemantauan dokumen rekam medis petugas filing di RSUD Dr.Moewardi menggunakan komputerisasi dan manual. Sedangkan dalam transaksi dokumen rekam medis petugas filing di RSUD Dr.Moewardi menggunakan tracer baik peminjaman dokumen rekam medis maupun pengembalian dokumen rekam medis.

4. Hasil dari SIMRS di RSUD Dr.Moewardi mengetahui jumlah dokumen rekam medis yang dipinjam, data dokumen rekam medis yang belum kembali, mengetahui penggunaan dokumen rekam medis per hari, mengetahui penggunaan dokumen rekam medis per bulan.

\section{DAFTAR PUSTAKA}

Amsyah Z. 2003. Manajemen Kearsipan, Jakarta: PT Gramedia Pustaka Utama. Hal. 202, 222

Garmelia E dan Erkadius. 2014. Supervise Fungsi Teknologi Informasi Kesehatan. Hatta, Gemala R. 2014. Pedoman Manajemen
Informasi Kesehatan Di Sarana Pelayanan Kesehatan, Jakarta: Universitas Indonesia (UI-Press). Hal. 340

Narbuko C dan Achmadi A. 2008. Metodologi Penelitian. Jakarta: Bumi Aksara.Hal. 44

Notoatmojo S. 2002. Metodologi Penelitian Kesehatan. Jakarta: Rineka Cipta.Hal. 93, 102 2013. 82/Menkes/Per/2013. Tentang Sistem manajemen Rumah Sakit.

Diakses : 20 januari 2015. Http:///www.buk. depkes.go.id

Nugroho A. 2014. Tinjauan Pengelolaan Ruang Filing di Rumah Sakit Panti Waluyo. [Karya Tulis Ilmiah]. Karanganyar: Apikes Mitra Husada. Hal. 46

Rustiyanto E. 2010. Statistik Rumah Sakit Untuk Pengambilan Keputusan, Yogyakarta: Graha Ilmu. Hal. 108

Rustiyanto E dan Rahayu, Warih A. 2011. Manajemen Filing Dokumen Rekam Medis Dan Informasi Kesehatan. Yogyakarta: Politeknik Kesehatan Permata Indonesia. Hal. 11, 17-18

Rustiyanto E. 2014. Sistem Informasi Manajemen Rumah Sakit. Yogyakarta: Politeknik Kesehatan Permata Indonesia. Hal. 29-37

Sudra, Rano I. 2013. Rekam Medis. Tangerang Selatan: Universitas Terbuka.Hal. 3.93-3.97

Sutarman. 2009. Pengantar Teknologi Informasi. Jakarta: Bumi Aksara. Hal. 14 